\title{
PEMBUATAN DAN PELATIHAN MEDIA INTERAKTIF MENGENAL BENTUK PADA TK FATAHILLAH
}

\author{
Za'imatun Niswati ${ }^{1)}$, Fanisya Alva Mustika ${ }^{2)}$ \\ ${ }^{1,2}$ Prodi Informatika, Fakultas Teknik dan Ilmu Komputer, Universitas Indraprasta PGRI
}

\begin{abstract}
Abstrak
Undang-Undang Sisdiknas no 20 tahun 2003 disebutkan bahwa Pendidikan anak usia dini adalah upaya pembinaan kepada anak sejak lahir sampai dengan usia 6 tahun dimana anak mendapat rangsangan pendidikan yang dapat meningkatkan pertumbuhan dan perkembangan jasmani dan rohani agar anak memiliki kesiapan dalam memasuki Pendidikan yang lebih tinggi. Peranan media dalam proses pembelajaran adalah meningkatkan kemampuan siswa dimana pada akhirnya dapat meningkatkan hasil belajar yang dicapainya. Keberhasilan proses Pendidikan salah satunya di dukung oleh media pembelajaran yang sesuai. Stimulus pada anak didik akan materi yang diajarkan guru dapat muncul dengan diberikannya media pembelajaran sesuai karakteristik anak didik. Kegiatan pengabdian masyarakat ini berupa pembuatan dan pelatihan media pembelajaran interaktif mengenal bentuk untuk mitra. Kegiatan ini bertujuan untuk meningkatkan kualitas pembelajaran dengan memanfaatkan penggunaan media pembelajaran interaktif pada proses belajar siswa di tempat mitra.
\end{abstract}

Keywords: Bentuk, Media interaktif, Pendidikan.

\begin{abstract}
The National Education System Law No. 20 of 2003 states that early childhood education is a coaching effort aimed at children from birth to 6 years of age where children receive educational stimuli that can increase physical and spiritual growth and development so that children have readiness to enter education higher. The role of media in the learning process is to improve students' abilities in learning which is expected to improve the learning outcomes they achieve. One of the successful implementation of the educational process is supported by appropriate learning media. Stimulus in students about the material taught by the teacher can be present by providing learning media according to the characteristics of students. This community service activity is in the form of making and training interactive learning media recognizing forms for partners. This activity aims to improve the quality of learning by utilizing the use of interactive learning media in the student learning process at partner places.
\end{abstract}

Keywords: Shape, Learning Media, Education.

Correspondence author: Fanisya Alva Mustika, funny.alva@gmail.com, Jakarta, Indonesia.

This work is licensed under a CC-BY-NC

\section{PENDAHULUAN}

Undang-Undang Sisdiknas no 20 tahun 2003 disebutkan bahwa Pendidikan anak usia dini adalah upaya pembinaan kepada anak sejak lahir sampai dengan usia 6 tahun dimana anak mendapat rangsangan pendidikan yang dapat meningkatkan pertumbuhan dan perkembangan jasmani dan rohani agar anak memiliki kesiapan dalam memasuki Pendidikan yang lebih tinggi (Saurina, 2016). Dalam pembelajaran pada anak usia dini 
tidak terlepas dari sebuah media. Peranan media dalam proses pembelajaran adalah meningkatkan kemampuan siswa dimana pada akhirnya dapat meningkatkan hasil belajar yang dicapainya. Banyak penelitian mengenai penggunaan media pembelajaran menyatakan bahwa proses dan hasil belajar pada siswa dengan menggunakan media pembelajaran dan tanpa menggunakan media pembelajaran menunjukkan perbedaan yang signifikan. Sehingga penggunaan media pembelajaran sangat dianjurkan dalam upaya meningkatkan kualitas pembelajaran Haryono, Anggraini, \& Muntominah, 2017). Keberhasilan proses Pendidikan salah satunya di dukung oleh media pembelajaran yang sesuai. Stimulus pada anak didik akan materi yang diajarkan guru dapat muncul dengan diberikannya media pembelajaran sesuai karakteristik anak didik (Maslich, 2016). Menurut Sudjana (2005:2) penggunaan media pembelajaran dapat meningkatkan hasil belajar siswa, sebab : a) Pengajaran menjadi lebih menarik dan dapat meningkatkan motivasi belajar siswa, b) materi pengajaran menjadi lebih jelas dan pada akhirnya meningkatkan penguasaan siswa terhadap suatu materi dengan baik, c) Metode pengajaran yang diberikan guru menjadi lebih bervariasi, tidak hanya melalui komunikasi verbal dan pidato oleh guru sehingga dengan penggunaan media pembelajaran siswa menjadi semangat belajar, d) siswa lebih banyak mempraktekkan kegiatan belajar, tidak monoton mendengarkan uraian guru di kelas, tetapi melakukan aktivitas mengamati, mendemonstrasikan, dan lain-lain (Kusumawati \& Mariono, 2016).

Pada TK Fatahillah belum memaksimalkan penggunaan media interaktif dalam proses pembelajaran. Oleh karena itu pelatihan pembuatan media pembelajaran interaktif sebagai alat bantu dalam kegiatan belajar siswa TK.

Permasalahan yang dihadapi mitra yaitu :

1. Mitra belum banyak memanfaatkan media pembelajaran interaktif dalam proses belajar mengajar.

2. Kurangnya materi pembelajaran yang menggunakan media interaktif yang dapat meningkatkan daya tarik siswa akan materi yang diajarkan guru.

\section{METODE PELAKSANAAN}

Kegiatan pengabdian kepada masyarakat dilaksanakan mulai bulan September 2019 sampai Januari 2020 di TK Fatahillah Jakarta. Langkah kerja dalam pelaksanaan program pengabdian masyarakat adalah :

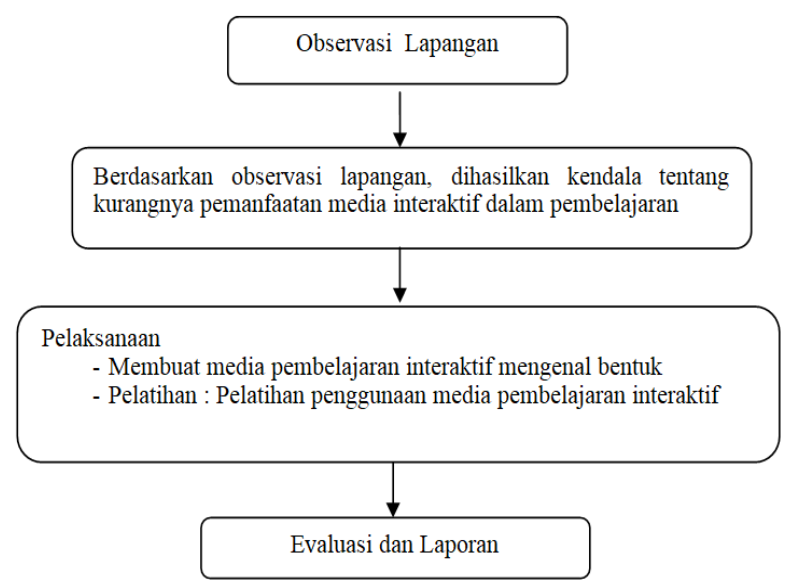

Gambar 1 Langkah pelaksanaan pengabdian kepada masyarakat 

berikut:

Bahan dan alat yang digunakan dalam program pengabdian ini adalah sebagai
a. Proyektor
b. Laptop
c. Modul

\section{HASIL DAN PEMBAHASAN}

\section{Pembuatan Media Interaktif}

Tim pelaksana pengabdian membuatkan media pembelajaran interaktif mengenal bentuk dan mengenal warna. Dimulai dengan mengumpulkan materi tentang bentuk, kemudian mencari materi dalam pembuatan media interaktif mengenal bentuk. Selanjutnya membuat media interaktif mengenal bentuk dengan menggunakan materi dan bahan yang sudah dikumpulkan.

\section{Pelatihan}

Tim pelaksana pengabdian masyarakat (pemateri) memberikan pelatihan penggunaan media interaktif yang sudah dibuat kepada guru-guru di TK Fatahillah (peserta pelatihan). Pemateri menjelaskan penggunaan media interaktif kepada peserta pelatihan, kemudian peserta mencoba sendiri media interaktif sesuai penjelasan pemateri.

\section{Sosialisasi}

Setelah sosialisasi kepada guru-guru, selanjutnya media interaktif disosialisasikan kepada siswa di TK Fatahillah. Guru menggunakan media interaktif untuk mengajarkan siswa mengenal bentuk. Kemudian siswa mencoba secara bergantian untuk menjawab kuis yang ada pada media interaktif tersebut.

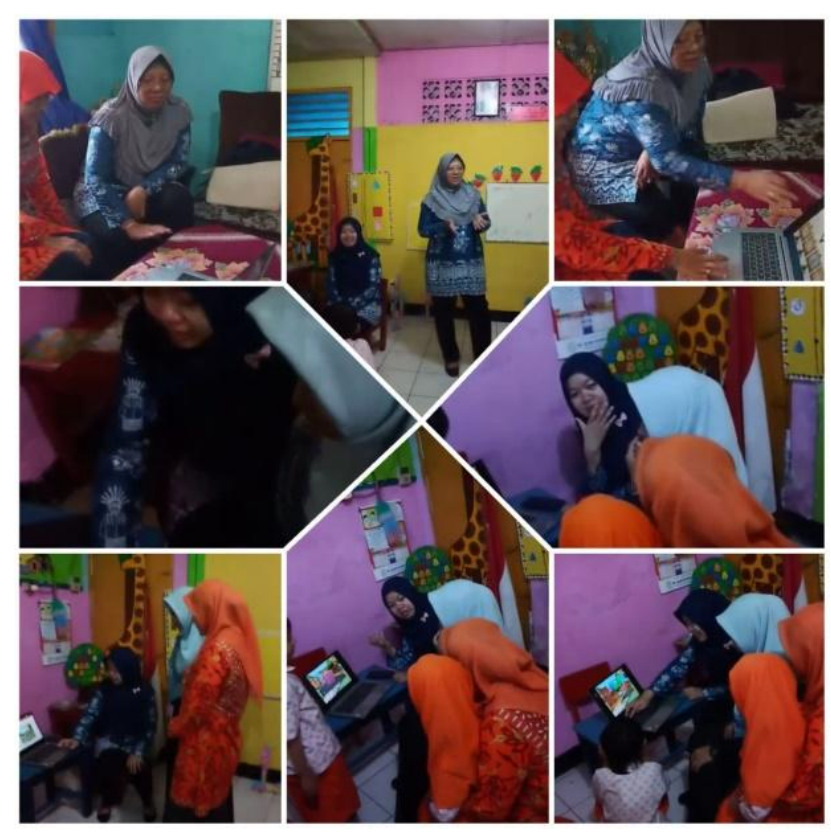

Gambar 2. Pelatihan Media Interaktif 


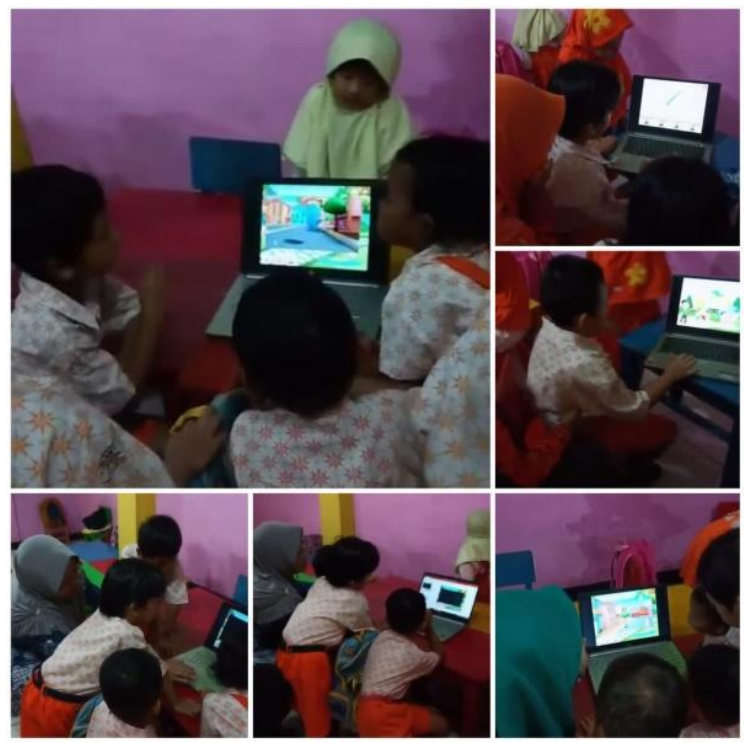

Gambar 3. Sosialisasi Media Interaktif

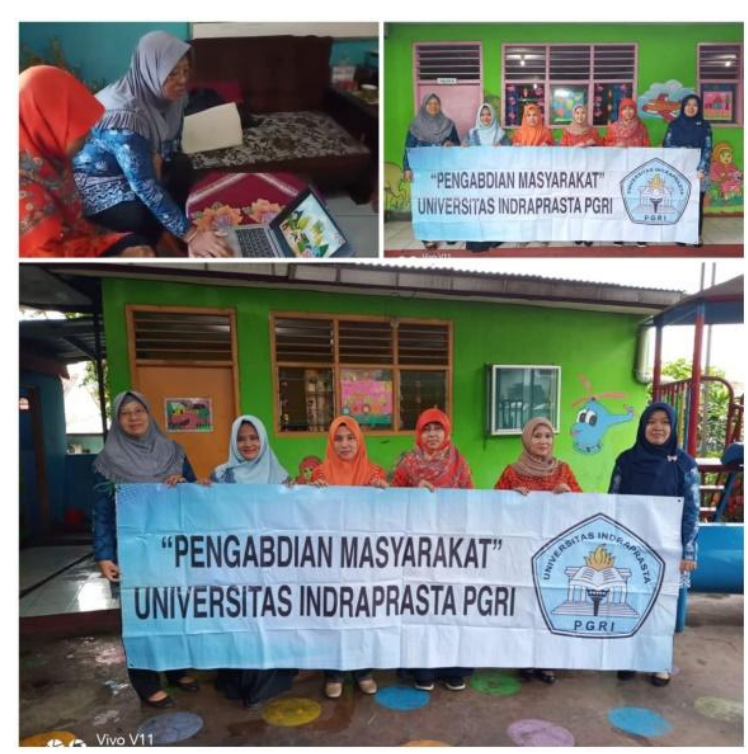

Gambar 4. Peserta Pengabdian kepada Masyarakat

\section{Tampilan Layar}

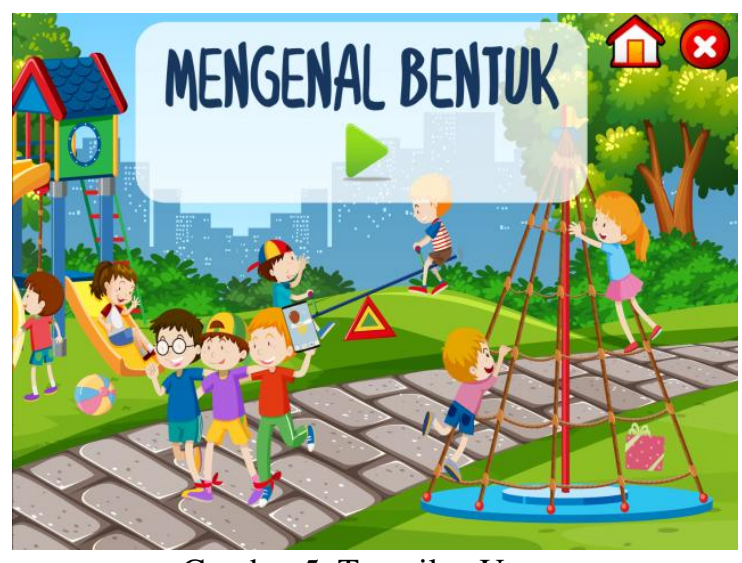

Gambar 5. Tampilan Utama 
Gambar di atas adalah tampilan utama pada salah satu media interaktif mengenal bentuk. Klik tombol memulai media interaktif tersebut. Setelah klik tombol tersebut maka akan masuk ke menu utama.

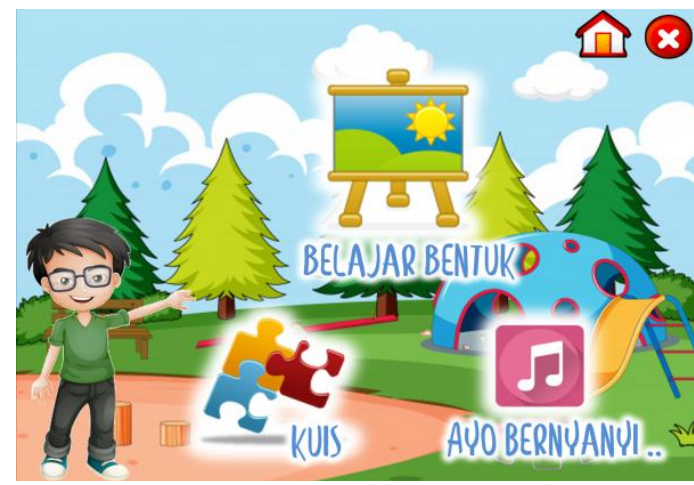

Gambar 6. Menu Utama

Gambar di atas adalah tampilan menu utama untuk media interaktif mengenal bentuk. Pada menu tersebut terdapat 3 pilihan, yaitu belajar bentuk, kuis, dan ayo bernyanyi. Klik pilihan belajar bentuk untuk masuk ke materi tentang bentuk. Klik pilihan kuis untuk masuk ke latihan atau kuis tentang bentuk. Klik pilihan ayo bernyanyi untuk masuk ke video bernyanyi mengenal bentuk.

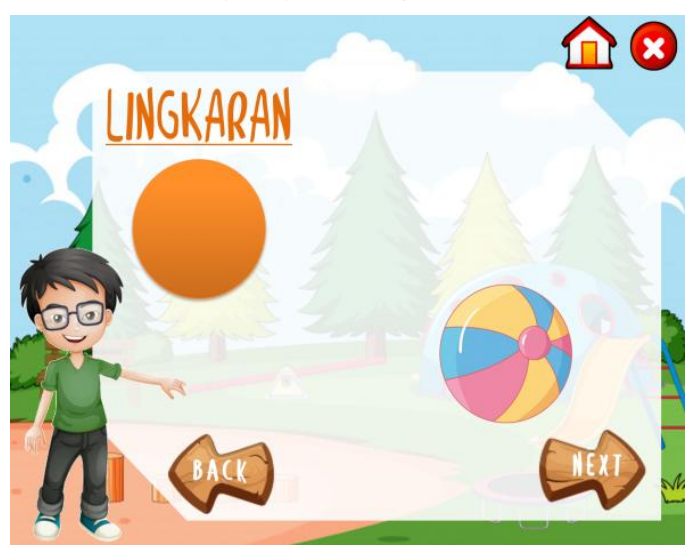

Gambar 7. Materi

Gambar di atas adalah salah tampilan materi mengenal bentuk yaitu lingkaran. Klik tombol back untuk kembali ke menu materi bentuk. Klik next untuk melanjutkan ke materi bentuk berikutnya.

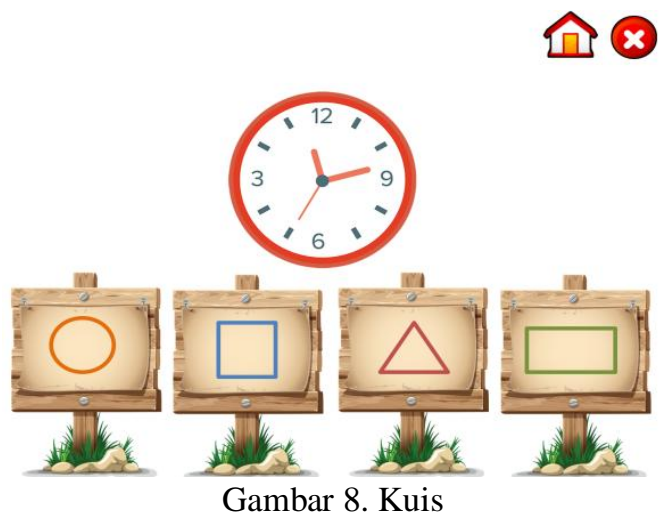


Gambar di atas adalah salah tampilan kuis mengenal bentuk. Klik pilihan jawaban bentuk sesuai dengan gambar yang ditampilkan.

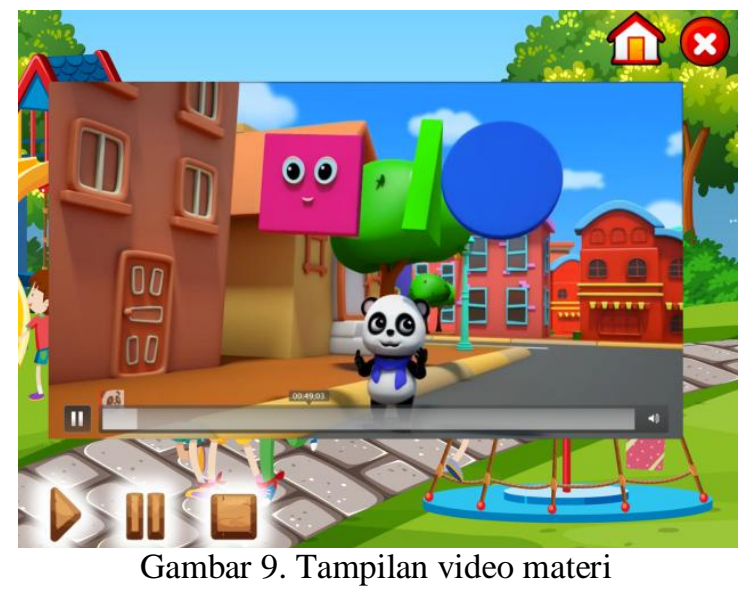

Gambar 9 adalah tampilan untuk pilihan ayo bernyanyi. Klik tombol untuk play atau mulai memainkan video. Klik untuk pause atau jeda video. Klik untuk stop atau berhenti memainkan video.

\section{SIMPULAN}

Pengabdian masyarakat yang dilakukan telah berjalan dengan baik dan dapat disimpulkan sebagai berikut:

1. Hasil dari pengabdian masyarakat berupa media pembelajaran interaktif mengenal bentuk.

2. Media pembelajaran interaktif yang sudah dibuat diberikan dan dibuat pelatihannya kepada guru TK Fatahillah.

3. Kegiatan sosialisasi pada TK Fatahillah tentang pembuatan media pembelajaran interaktif berjalan dengan baik dan membantu guru dalam kegiatan belajar mengajar agar lebih variatif.

\section{DAFTAR PUSTAKA}

Haryono, S. E., Anggraini, H., \& Muntominah, S. (2017). Pengembangan Media Pembelajaran untuk Anak Usia Dini dari Bahan Bekas. Seminar Nasional Hasil Penelitian Universitas Kanjuruhan Malang, 460-462.

Kusumawati, R., \& Mariono, A. (2016). Pengembangan Media Flashcard Tema Binatang untuk Kelompok B di Taman Kanak-kanak Asemjajar Surabaya. Jurnal Teknologi Pendidikan, Vol. 4(No. 1), 24-32.

Maslich, I. Y. (2016). Pengembangan Media Papan Pintar Angka (PAPIKA) bagi Anak Kelompok A Taman Kanak-kanak Nasional Samirono Caturtunggal Depok Sleman Yogyakarta. Universitas Negeri Yogyakarta. 
Saurina, N. (2016). Pengembangan Media Pembelajaran untuk Anak Usia Dini Menggunakan Augmented Reality. Jurnal IPTEK ISSN: 1411-7010, Vol. 20(No. 1, Mei 2016), 95-108. 